\title{
JOURNAL OF ENGINEERING SCIENCES
}

Volume 7, Issue 2 (2020)

Emovon I. (2020). A fuzzy multi-criteria decision-making approach for power generation problem analysis. Journal of Engineering Sciences, Vol. 7(2), pp. E26-E31, doi: 10.21272/jes.2020.7(2).e5

\section{A Fuzzy Multi-Criteria Decision-Making Approach for Power Generation Problem Analysis}

\author{
Emovon I.
}

Department of Mechanical Engineering, Federal University of Petroleum Resources, Effurun, Delta State, Nigeria

Article info:

Paper received:

The final version of the paper received:

Paper accepted online:
September 11, 2020

December 9, 2020

December 16, 2020

\author{
*Corresponding email: \\ emovon.ikuobase@fupre.edu.ng
}

\begin{abstract}
The abundance of different energy sources such as coal, natural gas, and crude oil are in the Africa region, yet one of the lowest electric energy per capita consumption. Different factors have been attributed to this abysmal energy failure in the literature, leading to her slow economic and industrial advancement. These factors include poor maintenance of power generation infrastructure and lack of policy continuity, among others. The purpose of this article is to prioritize these power generation problems for proper budgetary allocation by managers of electric power. The fuzzy VIKOR technique is presented for the evaluation and ranking of these power generation problems. The analysis showed that poor maintenance is the most critical challenge of bedeviling power generation in Nigeria. The Fuzzy VIKOR produces the same result as the classical VIKOR used previously in resolving the problem. The proposed technique addresses the challenge of uncertainty and subjectivity by applying linguistic variables in the decisionmaking process, which the classical VIKOR is incapable of handling.
\end{abstract}

Keywords: fuzzy logic, VIKOR technique, electric power, power generation.

\section{Introduction}

The power industry in Africa region is grossly underdeveloped [1]. It produces insufficient electric power to energies homes and industries. The inadequate power supply is one of the primary reasons for its slow economic and industrial growth [2]. Remarkably, most industries in Nigeria rely on individual electric power generators to power their buildings and machines, resulting in an increment in the industry's overhead cost [3]. The cost of energy is about $40 \%$ of production costs in the country [4]. Oher studies in the literature indicated that about 15 million family households in Nigeria have no access to national electric power, and even those with access constantly suffer from epileptic power supply [5]. Only $40 \%$ of Nigeria's population have access to electric power, and this is due to their closeness to the national grid [6].

Nigeria has a vast mix of energy resources such as natural gas, oil, and hydro for power generation but majorly relies on generating energy from oil and gas, contributing to over $70 \%$ of energy production [4]. Table 1 indicate different energy sources in Nigeria.

Despite the abundance of energy resources and concerted effort made by successive governments to improve Nigeria's power situation, its electricity per capita consumption is one of the lowest in the continent [8].
Table 1 - Energy source and reserve estimates [7]

\begin{tabular}{|l|l|}
\hline \multicolumn{1}{|c|}{ Energy Type } & \multicolumn{1}{c|}{ Reserves estimates } \\
\hline Crude oil & $36 \cdot 10^{6}$ barrels \\
\hline Natural gas & $185 \cdot 10^{9} \mathrm{ft}^{3}$ \\
\hline Coal & $2.75 \cdot 10^{6}$ tons \\
\hline Hydro & $14,750 \mathrm{MW}$ \\
\hline Solar radiation & $3.5-7.0 \mathrm{~kW} \cdot \mathrm{h} /\left(\mathrm{m}^{2} \cdot\right.$ day $)$ \\
\hline Wind energy & $2-4 \mathrm{~m} / \mathrm{s}$ \\
\hline Biomass & $144 \cdot 10^{6}$ tons $/$ year \\
\hline Wave and tidal energy & $150,000 \mathrm{TK} /(16.6 \times 106$ toe/year $)$ \\
\hline
\end{tabular}

Different reasons have been attributed to insufficient power generation in Nigeria in the literature. These include poor power plant maintenance [3,9], lack of energy mix [10], pipeline vandalism [11], obsolete and dilapidated plants [12], among others. The different power problems constitute a different degree of challenges to the overall power generation system. There is a need to ascertain each power problem's contribution to the power generation challenge for proper budgetary allocation.

The Multi-Criteria Decision Making (MCDM) method is a systematic approach for ranking alternatives concerning conflicting decision criteria. The MCDM approach generally applied in the literature are VIKOR, TOPSIS, PROMETHEE, and MOORA methods. The tools have been utilized individually, combined, and other tools such as Fuzzy Set Theory (FST). In work [3], Emovon and Samuel studied the combination of the 
variance and the VIKOR methods to prioritize the different power generation problems in Nigeria. The standard variance was used to analyze decision criteria weights, while the ranking of the alternative power problems was implemented with the VIKOR approach. In solving the same power problems, Emovon and Nwaoha [2] used the MOORA method combined with the AHP. The major challenge of these approaches is the need for precise estimates in their analysis, but experts' real-life information may be imprecise.

In this article, the FST is integrated with the VIKOR method to prioritize the different power generation problems. The approach is referred to as Fuzzy VIKOR. The FST in the methodology makes it possible to apply linguistic variables expressed in fuzzy numbers in dealing with the vagueness of judgment obtained from a group of experts (decision-makers).

\section{Research Methodology}

The VIKOR approach was developed using the compromise programming method, a type of MCDM [13]. The VIKOR technique was developed by Opricovic and Tzeng [14] for complex system multi-criteria optimization [15]. The technique focuses on prioritizing and choosing from a set of alternatives regarding conflicting decision criteria, requiring a compromise for resolving the conflict [16]. The technique performance index for ranking alternatives is based on the degree of closeness to the ideal alternative [17]. The VIKOR technique uses precise data as input into the decision-making process. However, human judgment's ambiguity makes it problematic for decision-makers to allocate a precise numerical value to alternatives against decision criteria [18]. For overcoming this challenge, the Fuzzy Set Theory (FST) is combined with VIKOR to form fuzzy VIKOR. In the Fuzzy VIKOR technique, linguistic variables are used by decision-makers to rate alternatives concerning decision criteria [13] and rate decision criteria. The linguistic variable can be expressed in Fuzzy Triangular Number (TFN). The TFN are three real numbers $(l, m, p)$ and $l, m$, and $p$, are indicating the lower, middle, and upper values of the TFN [19]. The linguistic scale for evaluating alternatives regarding decision criteria and evaluating decision criteria in this article is shown in Table 2.

Table 2 - Fuzzy linguistic variables and TFN for each criterion I [15] and alternative II [20, 21]

\begin{tabular}{|l|c|c|c|}
\hline \multirow{2}{*}{ Linguistic variable } & \multirow{2}{*}{ Abbreviation } & \multicolumn{2}{|c|}{ TFN } \\
\cline { 3 - 4 } & & I & II \\
\hline Very Low & VL & $0.0,0.1,0.2$ & $1,1,3$ \\
\hline Low & L & $0.1,0.2,0.3$ & $1,3,5$ \\
\hline Medium & M & $0.4,0.5,0.6$ & $3,5,7$ \\
\hline High & H & $0.7,0.8,0.9$ & $5,7,9$ \\
\hline Very High & VH & $0.8,0.9,1.0$ & $7,9,9$ \\
\hline
\end{tabular}

The Fuzzy VIKOR algorithm steps are as follows. The first stage is the formation of the aggregated decision matrix. In this article, the alternatives (power generation problems) performance ratings regarding decision criteria are determined based on experts' (decision-makers') opinions. Assuming $k$ decision-makers are to assign a rating to alternative $i$ against decision criterion $j$, the aggregated or combined rating of the decision-makers are evaluated as follows [13]:

$$
\tilde{u}_{i j}=\frac{1}{k}\left[\tilde{u}_{i j}^{1}+\tilde{u}_{i j}^{2}+, \ldots \tilde{u}_{i j}^{k}\right],
$$

where $\tilde{u}_{i j}^{k}$ is the $k$-th decision-maker rating of $i$-th alternative against $j$-th criterion.

In the fuzzy VIKOR analysis, it is expected weights are assigned to decision criteria by the $k$ decision-makers. The aggregated weight of each criterion can be evaluated by adding weights assigned by the individual decision-maker and then divide by the number of decision-makers as follows [22]:

$$
\widetilde{w}_{j}=\frac{1}{k}\left[\widetilde{w}_{j}^{1}+\widetilde{w}_{j}^{2}+, \ldots \widetilde{w}_{j}^{k}\right],
$$

where $\widetilde{w}_{j}^{k}$ is the fuzzy weight of criterion $j$ assigned by $k$-th decision-maker.

Having determined the aggregated fuzzy rating of alternative against decision criterion and the aggregated fuzzy weight of each criterion, the fuzzy decision problem is transformed into the following matrix form [13]:

$$
\widetilde{U}_{i j}=\left[\begin{array}{cccc}
\tilde{u}_{11} & \tilde{u}_{12} & \ldots & \tilde{u}_{1 n} \\
\tilde{u}_{21} & \tilde{u}_{22} & \ldots & \tilde{u}_{2 n} \\
\vdots & \vdots & \ddots & \vdots \\
\tilde{u}_{m 1} & \tilde{u}_{m 2} & \ldots & \tilde{u}_{m n}
\end{array}\right] ; \widetilde{w}_{j}=\left[\widetilde{w}_{1}+\cdots+\widetilde{w}_{n}\right],
$$

where $\tilde{u}_{i j}$ is the alternative, $i$, rating against criterion $j$ and $\widetilde{w}_{j}$ indicate the fuzzy weight of criterion $j=1,2,3, \ldots, n$.

The second stage is the evaluation of the fuzzy best $u_{j}^{*}$ and fuzzy worst $\tilde{u}_{j}^{-}$values. The fuzzy best $\tilde{u}_{j}^{*}=\left(l_{j}^{*}, m_{j}^{*}, p_{j}^{*}\right)$ and fuzzy worst $\tilde{u}_{j}^{o}=\left(l_{j}^{o}, m_{j}^{o}, p_{j}^{o}\right)$ values are evaluated for each criterion function as follows [15]:

$$
\tilde{u}_{j}^{*}=\max _{i}\left(\tilde{u}_{i j}\right) ; \tilde{u}_{j}^{o}=\min _{i}\left(\tilde{u}_{i j}\right) .
$$

Thirdly, the fuzzy difference between $\tilde{u}_{i j}$ and $\tilde{u}_{j}^{*}$ or $\tilde{u}_{j}^{o}$ is determined as follows [15]:

$$
d_{i j}=\left(\tilde{u}_{j}^{*}-\tilde{u}_{i j}\right) /\left(p_{j}^{*}-l_{j}^{o}\right) .
$$

At the fourth stage, evaluation of separation $\tilde{X}_{i}$ of alternative $i$ from fuzzy best value and separation $\tilde{Y}_{i}$ of alternative $i$ from fuzzy worst value are performed, respectively as follows [15]:

$$
\begin{aligned}
& \tilde{X}_{i}=\sum_{j=1}^{n} \widetilde{w}_{j}\left(\tilde{u}_{j}^{*}-\tilde{u}_{i j}\right) /\left(p_{j}^{*}-l_{j}^{o}\right) ; \\
& \tilde{Y}_{i}=\max _{j}\left[\widetilde{w}_{j}\left(\tilde{u}_{j}^{*}-\tilde{u}_{i j}\right) /\left(p_{j}^{*}-l_{j}^{o}\right)\right] .
\end{aligned}
$$

At the next stage, fuzzy VIKOR performance index $\tilde{Q}_{i}$ is determined as follow [15]:

$$
\begin{gathered}
\tilde{Q}_{i}=v\left(\tilde{X}_{i}-\tilde{X}^{*}\right) /\left(X^{o p}-X^{* l}\right)+ \\
+(1-v)\left(\tilde{Y}_{i}-\tilde{Y}^{*}\right) /\left(Y^{o p}-Y^{* l}\right)
\end{gathered}
$$


where $\tilde{X}^{*}=\min _{i}\left(\tilde{X}_{i}\right), X^{o p}=\max _{i}\left(X_{i}^{p}\right), \tilde{Y}^{*}=\min _{i}\left(\tilde{Y}_{i}\right)$, $Y^{o p}=\max _{i}\left(Y_{i}^{p}\right)$, and $v$ indicates the decision-making strategy of the maximum group utility weight $v$ is assigned with a value of 0.5 .

The last stage is the defuzzification of $\widetilde{Q}_{i}=\left(l_{i}, m_{i}, p_{i}\right)$ values and conversion into a crisp number $Q_{i}$ as follows [23]:

$$
\operatorname{Crisp}\left(\widetilde{Q}_{i}\right)=Q_{i}=\frac{l+4 m+p}{6} .
$$

The defuzzification technique is referred to as graded mean integration.

(7) The alternatives are ranked based on $Q_{i}$ and the alternative with the minimum value being optimal.

\section{Results and Discussion}

In this article, nine power generation problems are ranked concerning three decision criteria. The problem has been studied previously by [3] using a combination of the standard variance and VIKOR methods. The authors ranked the power problems with the VIKOR method, and the decision criteria weightage was evaluated with the standard variance approach. The power generation problems they identified are poor maintenance (A1), corruption (A2), inadequate funding (A3), militant activities (A4), inadequate human resources (A5), wrong location of power stations (A6), Drought (A7), poor pricing of electricity (A8), and lack of policy continuity (A9). The performance of each alternative was evaluated concerning decision criteria; environmental pollution (EP), critical power assets (CAD), and power generation output (PGO). Two experts assigned performance rating to the alternatives against decision criteria using a 5-point Likert scale as indicated in Table 3 with the average score used to form the decision matrix, which the authors applied in analyzing the VIKOR method. However, in this article, the Fuzzy VIKOR method is utilized to resolve the problem.

To achieve this, aim the 5-point fuzzy scale for rating alternatives against decision criteria in Table 2 was used to get the equivalent of DM1 and DM2 ratings in the linguistic form. For example, DM1 rating of A1 against decision criteria EP is 2, the equivalent in fuzzy linguistic scale is $L$, DM1 rating of A1 against decision criteria CAD is 5 , the equivalent in fuzzy linguistic is $V H$. The DM1 and DM2 fuzzy linguistic ratings of alternatives against decision criteria are presented in Table 4. Since the linguistic variables are expresses in the TFN, the corresponding TFN are also shown in Table 4.

Table 3 - Decision Makers (DM) average rating of power generation problems [3]

\begin{tabular}{|l|c|c|c|c|c|c|c|c|c|}
\hline \multirow{2}{*}{ Power generation problems } & \multicolumn{3}{|c|}{ DM1 } & \multicolumn{3}{c|}{ DM2 } & \multicolumn{3}{c|}{ Average Score } \\
\cline { 2 - 11 } & EP & CAD & PGO & EP & CAD & PGO & EP & CAD & PGO \\
\hline Poor maintenance (A1) & 2 & 5 & 5 & 3 & 5 & 5 & 2.5 & 5.0 & 5.0 \\
\hline Corruption (A2) & 1 & 4 & 5 & 3 & 2 & 5 & 2.0 & 3.0 & 5.0 \\
\hline Inadequate funding (A3) & 3 & 3 & 3 & 2 & 4 & 5 & 2.5 & 3.5 & 4.0 \\
\hline Militant activities (A4) & 5 & 3 & 5 & 3 & 4 & 3 & 4.0 & 3.5 & 4.0 \\
\hline Inadequate manpower (A5) & 4 & 4 & 4 & 2 & 2 & 2 & 3.0 & 3.0 & 3.0 \\
\hline Wrong location (A6) & 3 & 2 & 2 & 3 & 2 & 4 & 3.0 & 2.0 & 3.0 \\
\hline Drought (A7) & 1 & 1 & 2 & 1 & 1 & 2 & 1.0 & 1.0 & 2.0 \\
\hline Poor pricing of electricity (A8) & 2 & 3 & 1 & 2 & 2 & 2 & 2.0 & 2.5 & 1.5 \\
\hline Lack of policy continuity (A9) & 1 & 3 & 3 & 2 & 3 & 3 & 1.5 & 3.0 & 3.0 \\
\hline
\end{tabular}

Table 4 - Decision Makers (DM) alternatives linguistic rating and equivalent TFN

\begin{tabular}{|c|c|c|c|c|c|c|c|}
\hline \multirow{2}{*}{$\begin{array}{c}\text { Decision } \\
\text { Makers (DM) }\end{array}$} & \multirow{2}{*}{$\begin{array}{c}\text { Power generation } \\
\text { problems }\end{array}$} & \multicolumn{3}{|c|}{ Linguistic variable } & \multicolumn{3}{|c|}{ TFN } \\
\hline & & EP & CAD & PGO & EP & CAD & PGO \\
\hline \multirow{9}{*}{ DM1 } & A1 & $\mathrm{L}$ & $\mathrm{VH}$ & $\mathrm{VH}$ & $(1,3,5)$ & $(7,9,9)$ & $(7,9,9)$ \\
\hline & $\mathrm{A} 2$ & VL & $\mathrm{H}$ & $\mathrm{VH}$ & $(1,1,3)$ & $(5,7,9)$ & $(7,9,9)$ \\
\hline & $\mathrm{A} 3$ & $\mathrm{M}$ & $\mathrm{M}$ & $\mathrm{M}$ & $(3,5,7)$ & $(3,5,7)$ & $(3,5,7)$ \\
\hline & A4 & $\mathrm{VH}$ & $\mathrm{M}$ & $\mathrm{VH}$ & $(7,9,9)$ & $(3,5,7)$ & $(7,9,9)$ \\
\hline & A5 & $\mathrm{H}$ & $\mathrm{H}$ & $\mathrm{H}$ & $(5,7,9)$ & $(5,7,9)$ & $(5,7,9)$ \\
\hline & A6 & $\mathrm{M}$ & $\mathrm{L}$ & $\mathrm{L}$ & $(3,5,7)$ & $(1,3,5)$ & $(1,3,5)$ \\
\hline & A7 & VL & VL & $\mathrm{L}$ & $(1,1,3)$ & $(1,1,3)$ & $(1,3,5)$ \\
\hline & A8 & $\mathrm{L}$ & $\mathrm{M}$ & $\mathrm{VL}$ & $(1,3,5)$ & $(3,5,7)$ & $(1,1,3)$ \\
\hline & A9 & VL & $\mathrm{M}$ & $M$ & $(1,1,3)$ & $(3,5,7)$ & $(3,5,7)$ \\
\hline \multirow{9}{*}{ DM2 } & A1 & $\mathrm{M}$ & $\mathrm{VH}$ & $\mathrm{VH}$ & $(3,5,7)$ & $(7,9,9)$ & $(7,9,9)$ \\
\hline & $\mathrm{A} 2$ & $\mathrm{M}$ & $\mathrm{L}$ & $\mathrm{VH}$ & $(3,5,7)$ & $(1,3,5)$ & $(7,9,9)$ \\
\hline & A3 & $\mathrm{L}$ & $\mathrm{H}$ & $\mathrm{VH}$ & $(1,3,5)$ & $(5,7,9)$ & $(7,9,9)$ \\
\hline & A4 & $\mathrm{M}$ & $\mathrm{H}$ & $\mathrm{M}$ & $(3,5,7)$ & $(5,7,9)$ & $(3,5,7)$ \\
\hline & A5 & $\mathrm{L}$ & $\mathrm{L}$ & $\mathrm{L}$ & $(1,3,5)$ & $(1,3,5)$ & $(1,3,5)$ \\
\hline & A6 & M & $\mathrm{L}$ & $\mathrm{H}$ & $(3,5,7)$ & $(1,3,5)$ & $(5,7,9)$ \\
\hline & A7 & VL & VL & $\mathrm{L}$ & $(1,1,3)$ & $(1,1,3)$ & $(1,3,5)$ \\
\hline & A8 & $\mathrm{L}$ & $\mathrm{L}$ & $\mathrm{L}$ & $(1,3,5)$ & $(1,3,5)$ & $(1,3,5)$ \\
\hline & A9 & $\mathrm{L}$ & $\mathrm{M}$ & $\mathrm{M}$ & $(1,3,5)$ & $(3,5,7)$ & $(3,5,7)$ \\
\hline
\end{tabular}


Decision criteria importance is generally not the same, and criteria weight determination is required in the fuzzy decision-making process. One technique of determining weight is decision-makers' use to assign the degree of importance to decision criteria using the fuzzy linguistic scale in Table 1. The decision-makers' assigned weights will then be aggregated with equation (2) to form aggregated weights of criteria. However, for unbiased comparison of the fuzzy VIKOR with the classical VIKOR method, the same decision criteria weights [3] use for the classical VIKOR are applied in this article for the fuzzy VIKOR analysis. The decision criteria: EP, CAD, and PGO weights are $0.2477,0.3455$, and 0.4068 , respectively.

The first step in the fuzzy VIKOR analysis is the formation of the aggregated decision matrix. Hence, applying equation (1), the fuzzy rating of alternatives by the DM1 and DM2 are synthesized to form a decision matrix shown in Table 5. The values of fuzzy best and worst then evaluated using equation (2). The result produced is presented in Table 6. The fuzzy difference (3) and the result are shown in Table 7.
Table 5 - Aggregated rating of alternatives against decision criteria (decision matrix)

\begin{tabular}{|c|c|c|c|}
\hline $\begin{array}{c}\text { Power } \\
\text { generation } \\
\text { problems }\end{array}$ & EP & CAD & PGO \\
\hline A1 & $(2,4,6)$ & $(7,9,9)$ & $(7,9,9)$ \\
\hline A2 & $(2,3,5)$ & $(3,5,7)$ & $(7,9,9)$ \\
\hline A3 & $(2,4,6)$ & $(4,6,8)$ & $(5,7,9)$ \\
\hline A4 & $(5,7,8)$ & $(4,6,8)$ & $(5,78)$ \\
\hline A5 & $(3,5,7)$ & $(3,5,7)$ & $(3,5,7)$ \\
\hline A6 & $(3,5,7)$ & $(1,3,5)$ & $(3,5,7)$ \\
\hline A7 & $(1,1,3)$ & $(1,1,3)$ & $(1,3,5)$ \\
\hline A8 & $(1,3,5)$ & $(2,4,6)$ & $(1,2,4)$ \\
\hline A9 & $(1,2,4)$ & $(3,5,7)$ & $(3,5,7)$ \\
\hline
\end{tabular}

Table 6 - Fuzzy best and worst values for criterion function

\begin{tabular}{|c|c|c|c|}
\hline Alternatives & $\mathrm{C} 1$ & $\mathrm{C} 2$ & $\mathrm{C} 3$ \\
\hline$\tilde{u}_{j}^{*}$ & $(5,7,8)$ & $(7,9,9)$ & $(7,9,9)$ \\
\hline$\tilde{u}_{j}^{-}$ & $(1,1,3)$ & $(1,1,3)$ & $(1,2,4)$ \\
\hline
\end{tabular}

Table 7 - Fuzzy difference between decision matrix and fuzzy best or worst values

\begin{tabular}{|c|c|c|c|}
\hline Indicator & EP & CAD & PGO \\
\hline A1 & $(-0.143,0.429,0.857)$ & $(-0.250,0.000,0.250)$ & $(-0.250,0.000,0.250)$ \\
\hline A2 & $(0.000,0.571,0.857)$ & $(0.000,0.500,0.750)$ & $(-0.250,0.000,0.250)$ \\
\hline A3 & $(-0.143,0.429,0.857)$ & $(-0.125,0.375,0.625)$ & $(-0.250,0.250,0.500)$ \\
\hline A4 & $(-0.429,0.000,0.429)$ & $(-0.125,0.375,0.625)$ & $(-0.125,0.250,0.500)$ \\
\hline A5 & $(-0.286,0.286,0.714)$ & $(0.000,0.500,0.750)$ & $(0.000,0.500,0.750)$ \\
\hline A6 & $(-0.286,0.286,0.714)$ & $(0.250,0.750,1.000)$ & $(0.000,0.500,0.750)$ \\
\hline A7 & $(0.286,0.857,1.000)$ & $(0.500,1.000,1.000)$ & $(0.250,0.750,1.000)$ \\
\hline A8 & $(0.000,0.571,1.000)$ & $(0.125,0.625,0.875)$ & $(0.375,0.875,1.000)$ \\
\hline A9 & $(0.143,0.714,1.000)$ & $(0.000,0.500,0.750)$ & $(0.000,0.500,0.750)$ \\
\hline
\end{tabular}

The values of $\tilde{X}^{*}$ and $\tilde{Y}$ are evaluated by equations (4)(5). The results are shown in Table 8 . Then the values of $\tilde{X}^{*}, X^{o p}, X^{* l}, \tilde{Y}^{*}, Y^{o p}$ are summarized in Table 9.

Table 8 - Measure of separation of alternatives $i$ from fuzzy best and worst values

\begin{tabular}{|c|c|c|}
\hline Indicator & $\tilde{X}_{i}$ & $\tilde{Y}_{i}$ \\
\hline A1 & $(-0.223,0.106,0.400)$ & $(-0.035,0.106,0.212)$ \\
\hline A2 & $(-0.102,0.314,0.573)$ & $(0.000,0.173,0.259)$ \\
\hline A3 & $(-0.180,0.337,0.632)$ & $(-0.035,0.130,0.216)$ \\
\hline A4 & $(-0.200,0.231,0.525)$ & $(-0.043,0.130,0.216)$ \\
\hline A5 & $(-0.071,0.447,0.741)$ & $(0.000,0.203,0.305)$ \\
\hline A6 & $(0.016,0.533,0.828)$ & $(0.086,0.259,0.346)$ \\
\hline A7 & $(0.345,0.863,1.000)$ & $(0.173,0.346,0.407)$ \\
\hline A8 & $(0.196,0.713,0.957)$ & $(0.153,0.356,0.407)$ \\
\hline A9 & $(0.035,0.553,0.812)$ & $(0.035,0.203,0.305)$ \\
\hline
\end{tabular}

To evaluate the values of $\tilde{Q}_{i}$, equation (6) is applied. The input data is presented in Tables 8-9. The evaluated results are shown in Table 10.
Table $9-\tilde{X}^{*}, X^{o p}, X^{* l}, \tilde{Y}^{*}, Y^{o p}$ and $Y^{* l}$ values

\begin{tabular}{|c|c|}
\hline Parameter & Value \\
\hline$\tilde{X}^{*}$ & $(-0.223,0.106,0.400)$ \\
\hline$X^{o p}$ & 1.000 \\
\hline$X^{* l}$ & -0.223 \\
\hline$\tilde{Y}^{*}$ & $(-0.043,0.106,0.212)$ \\
\hline$Y^{o p}$ & 0.407 \\
\hline$Y^{* l}$ & -0.043 \\
\hline
\end{tabular}

Table 10 - Fuzzy VIKOR ranking index

\begin{tabular}{|c|c|c|c|}
\hline Indicator & $\widetilde{Q}_{i}$ & $Q i$ & Rank \\
\hline A1 & $(-0.5302,0.0000,0.5389)$ & 0.0014 & 1 \\
\hline A2 & $(-0.4411,0.1591,0.6615)$ & 0.1428 & 4 \\
\hline A3 & $(-0.5125,0.1205,0.6374)$ & 0.1012 & 3 \\
\hline A4 & $(-0.5293,0.0771,0.5940)$ & 0.0622 & 2 \\
\hline A5 & $(-0.4285,0.2473,0.7812)$ & 0.2237 & 5 \\
\hline A6 & $(-0.2972,0.3445,0.8614)$ & 0.3237 & 7 \\
\hline A7 & $(-0.0665,0.5752,1.0000)$ & 0.5391 & 9 \\
\hline A8 & $(-0.1500,0.5257,0.9824)$ & 0.4892 & 8 \\
\hline A9 & $(-0.3458,0.2907,0.8101)$ & 0.2712 & 6 \\
\hline
\end{tabular}

Finally, the values of $\tilde{Q}_{i}$ are deffusified using equation (7) to obtained $Q i$ values and the ranking of alternatives performed based on the $Q i$ values as indicated in Table 10 . 
The ranking of the power generation problems based on the $Q i$ performance values in ascending order is A1, A2, A3, A2, A5, A9, A6, A8, A7. The most critical power generation problem in Nigeria is A1 (poor maintenance). The second most critical problem is A2 (corruption), and the minor critical problem is A7 (drought). From the analysis results, it is recommended Nigeria power system managers should invest in power system infrastructure maintenance massively and curb corruption in the system to minimize the power problem in Nigeria. The result produced from this analysis was the same as a result produced by Emovon and Samuel [3] using the classical VIKOR method. The Fuzzy VIKOR methodology can manage vagueness and subjectivity in the decision-making process using linguistic variables that the classical VIKOR is incapable of doing.

\section{Conclusions}

In this article, the fuzzy VIKOR method is presented to rank the different power generation problems to determine the more critical challenge for proper budgetary allocation by the power generation system managers. The fuzzy VIKOR analysis indicated that A1 (poor maintenance) is the most critical power generation problem, having scored the lowest fuzzy VIKOR index value of 0.0014 , while the least critical problem is A7 (drought), having scored the highest index value of 0.5391 . The result generated from the fuzzy VIKOR method is the same as those obtained by Emovon and Samuel with the classical VIKOR method. The fuzzy VIKOR has the advantage of using a linguistic variable that is simpler for measuring human judgment than the use of precise information in the classical VIKOR, which is unrealistic in real-life application.

\section{References}

1. Ogbonnaya, C., Abeykoon, C., Damo, U. M., Turan, A. (2019). The current and emerging renewable energy technologies for power generation in Nigeria: A review. Thermal Science and Engineering Progress, Vol. 13, 100390.

2. Emovon, I. and Nwaoha, T. C. (2018). Power generation problems ranking using a combination of AHP and MOORA techniques, Annals of the Faculty of Engineering Hunedoara-International Journal of Engineering, Vol. 16(2), pp. 13-18.

3. Emovon, I., Samuel, O. D. (2017). An integrated Statistical Variance and VIKOR methods for prioritising power generation problems in Nigeria. Journal of Engineering and Technology, Vol. 8(1), pp. 92-101.

4. Aliyu, A. S., Ramli, A. T., Saleh, M.A. (2013). Nigeria electricity crisis: Power generation capacity expansion and environmental ramifications. Energy, Vol. 61, pp. 354-367.

5. Monyei, C. G., Adewumi, A. O., Obolo, M. O., Sajou, B. (2018). Nigeria's energy poverty: Insights and implications for smart policies and framework towards a smart Nigeria electricity network. Renewable and Sustainable Energy Reviews, Vol. 81, pp. 1582-1601.

6. Okoye, C. O., Taylan, O., Baker, D. K. (2016). Solar energy potentials in strategically located cities in Nigeria: Review, resource assessment and PV system design. Renewable and Sustainable Energy Reviews, Vol. 55, pp. 550-566.

7. Ibitoye, F. I., Adenikinju, A., 2007. Future demand for electricity in Nigeria. Applied Energy, Vol. 84(5), pp.492-504.

8. Olaoye, T., Ajilore, T., Akinluwade, K., Omole, F., Adetunji, A. (2016). Energy crisis in Nigeria: Need for renewable energy mix. American Journal of Electrical and Electronic Engineering, Vol. 4(1), pp. 1-8.

9. Onohaebi, O. S., Lawal, Y. O. (2010). Poor maintenance culture; the bane to electric power generation in Nigeria. Journal of Economics and Engineering, pp. 28-33.

10. Idigbe, K. I., Igbinovia, S. O. (2010). Assessing the sustainability of electric power in Nigeria: a case study of the IPPs. $J$ Econ Eng, 70-7.

11. Sule, A. H. (2010). Major factors affecting electricity generation, transmission and distribution in Nigeria. International Journal of Engineering and Mathematical Intelligence, Vol. 1(1), pp. 164-169.

12. Adenikinju, A. F. (2003). Electric infrastructure failures in Nigeria: A survey-based analysis of the costs and adjustment responses. Energy Policy, Vol. 31(14), pp. 1519-1530.

13. Kaya, T., Kahraman, C. (2010). Multicriteria renewable energy planning using an integrated fuzzy VIKOR \& AHP methodology: The case of Istanbul. Energy, Vol. 35(6), pp. 2517-2527.

14. Opricovic, S., Tzeng, G. H. (2004). Compromise solution by MCDM methods: A comparative analysis of VIKOR and TOPSIS. European Journal of Operational Research, Vol. 156(2), pp. 445-455.

15. Banaeian, N., Mobli, H., Fahimnia, B., Nielsen, I. E., Omid, M. (2018). Green supplier selection using fuzzy group decision making methods: A case study from the agri-food industry. Computers and Operations Research, Vol. 89, pp. 337-347.

16. Shemshadi, A., Shirazi, H., Toreihi, M., Tarokh, M. J. (2011). A fuzzy VIKOR method for supplier selection based on entropy measure for objective weighting. Expert Systems with Applications, Vol. 38(10), pp. 12160-12167.

17. Opricovic, S. (1998). Multicriteria optimization of civil engineering systems. Faculty of Civil Engineering, Vol. 2(1), pp. 5-21.

18. Carpitella, S., Certa, A., Izquierdo, J., La Fata, C. M. (2018). A combined multi-criteria approach to support FMECA analyses: A real-world case. Reliability Engineering and System Safety, Vol. 169, pp. 394-402. 
19. Vinodh, S., Vimal, K. E. K. (2012). Thirty criteria based leanness assessment using fuzzy logic approach. The International Journal of Advanced Manufacturing Technology, Vol. 60(9-12), pp. 1185-1195.

20. Kore, N. B., Ravi, K., Patil S. B. (2017). A simplified description of FUZZYTOPSIS method for Multicriteria Decision Making. International Research Journal of Engineering and Technology, Vol. 4(5), pp. 1-4.

21. Azizi, A., Aikhuele, D. O., Souleman, F. S. (2015). A Fuzzy TOPSIS model to rank automotive suppliers. Procedia Manufacturing, Vol. 2, pp. 159-164.

22. Wang, T. C., Liang, J. L., Ho, C. Y. (2006). Multi-criteria decision analysis by using fuzzy VIKOR. IEEE 2006 International Conference on Service Systems and Service Management, Vol. 2, pp. 901-906.

23. Yong, D. (2006). Plant location selection based on fuzzy TOPSIS. The International Journal of Advanced Manufacturing Technology, Vol. 28(7-8), pp. 839-844. 